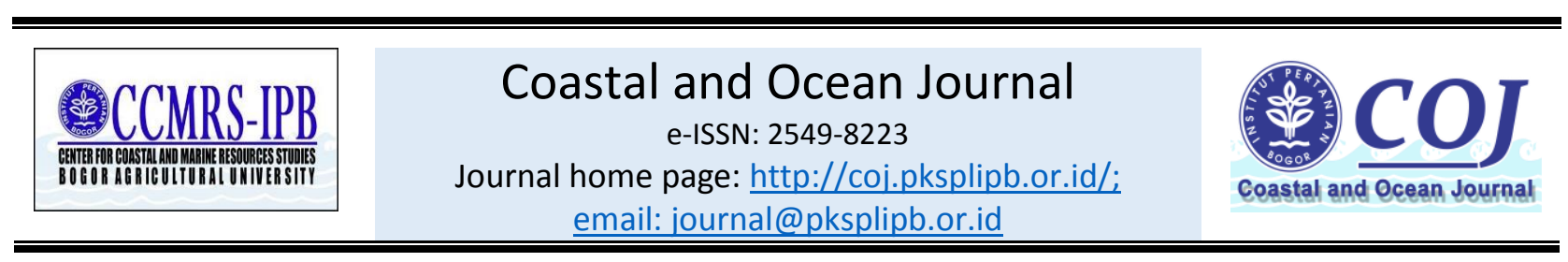

ANALISIS SPATIAL IDENTIFIKASI LOKASI KAWASAN KONSERVASI PERAIRAN YANG IDEAL DI KOTA TUAL, PROVINSI MALUKU

\title{
SPATIAL ANALYSIS IDENTIFICATION OF IDEAL AREAS CONSERVATION LOCATION IN TUAL CITY, MALUKU PROVINCE
}

\author{
Taufik Abdillah a*, Christian Novia N. Handayani a, Dirga Daniel a \\ aWWF-Indonesia \\ E-mail: tabdillah@wwf.id, chandayani@wwf.id,ddaniel@wwf.id
}

\begin{abstract}
Tual City is the one of eleven districts / cities in Maluku Province. The city includes an archipelago town, has 66 islands divided into 3 island clusters, covering the cluster of Kur islands, Tayando Tam and Dullah. The sea area reaches $19,088 \mathrm{Km}^{2}$, while the land area is $254.39 \mathrm{~km}^{2}$. The size of the sea in this area indicates the high utilization potential of both fisheries and tourism sector. Based on these, needed resources management the coastal and marine resources effectively, one of them by developing conservation area in coastal area and small islands. Tual City took the initiative to allocate part of its area to be reserved as a marine conservation area. The target of the formation of urban water conservation area Tual is the protection of important marine habitats consisting of coral reefs, seagrass and mangrove, sea turtle nesting beaches and connectivity larvae. This study was conducted to obtain potential locations of marine conservation areas that have high conservation value. Analysis of spatial data using Marxan analysis. This analysis was chosen because it provides the best solution for determining locations that have high conservation value. The results of the study indicate that the area of selected high frequency locations is 125,000 hectares, while 40,000 hectares and 64,000 hectares low. Selected high-frequency locations are in the cluster of Kur islands, Tayando Tam and in the waters north of Mas Island and Bair. Based on this study, the cluster of Kur and Tayando Tam islands become the recommended sites requiring the management of marine conservation areas as they are representative of all conservation targets.
\end{abstract}

Keyword: Marine Protected Area, Marxan, and Tual City

\begin{abstract}
ABSTRAK
Kota Tual merupakan salah satu dari sebelas kabupaten/kota yang ada di Provinsi Maluku. Kota ini termasuk kota kepulauan, memiliki 66 pulau yang dibagi menjadi 3 gugus pulau, meliputi gugus pulaupulau Kur, Tayando Tam dan Dullah. Luas laut mencapai $19.088 \mathrm{Km}^{2}$ sedangkan luas darat $254.39 \mathrm{Km}^{2}$. Besarnya luasan laut di daerah ini menandakan tingginya potensi pemanfaatan baik sektor perikanan maupun pariwisata. Berdasarkan hal tersebut diperlukan pengelolaan sumberdaya pesisir dan laut yang efektif, salah satunya dengan mengembangkan kawasan konservasi di wilayah pesisir dan pulau-pulau kecil. Kota Tual berinisiatif untuk mengalokasikan sebagian daerahnya untuk dicadangkan menjadi kawasan konservasi perairan. Target pembentukan kawasan konservasi perairan Kota Tual yaitu perlindungan terhadap habitat laut penting terdiri dari terumbu karang, lamun dan mangrove, pantai peneluran penyu dan larva connectivity. Kajian ini dilakukan guna mendapatkan lokasi potensial kawasan konservasi perairan yang memiliki nilai konservasi yang tinggi. Analisis data spatial menggunakan analisis Marxan. Analisis ini dipilih karena memberikan solusi terbaik untuk menentukan lokasi yang memiliki nilai konservasi yang tinggi. Hasil kajian menunjukkan bahwa luas lokasi frekuensi terpilih tinggi yaitu 125.000 hektar, sedang 40.000 hektar dan rendah 64.000 hektar. Lokasi frekuensi tinggi terpilih berada di gugus pulau-pulau Kur, Tayando Tam dan di perairan sebelah utara Pulau Mas dan Bair. Berdasarkan kajian ini, gugus pulau-pulau Kur dan Tayando Tam menjadi lokasi rekomendasi yang memerlukan adanya pengelolaan kawasan konservasi perairan karena memiliki keterwakilan dari seluruh target konservasi.
\end{abstract}

Kata Kunci: Kawasan Konservasi Perairan dan Pulau-Pulau Kecil, Marxan, Kota Tual 


\section{PENDAHULUAN}

Kota Tual merupakan salah satu dari sebelas kabupaten/kota yang ada di Provinsi Maluku. Kota ini termasuk kota kepulauan dengan 66 pulau yang meliputi 3 gugus pulau yaitu gugus pulau Kur, Tayando Tam dan Dullah. Luas total wilayah Kota Tual yaitu $\pm 19.342,39 \mathrm{Km}^{2}$, wilayah lautan lebih luas dibandingkan dengan wilayah daratan. Wilayah laut \pm $19.088 \mathrm{Km}^{2}$ atau sekitar 98,68\% dari luas total sedangkan luas wilayah darat 254.39 $\mathrm{Km}^{2}$ atau sekitar 1,32\% (BPS, 2016).

Wilayah laut yang luas serta banyaknya pulau-pulau yang dimiliki menandakan tingginya potensi yang ada, baik di pesisir maupun perairan laut Kota Tual. Masyarakatpun memiliki tingkat ketergantungan akan sumberdaya perikanan yang tinggi. Dengan semakin meningkatnya jumlah penduduk di kota ini maka pemanfaatan dan eksploitasi terhadap sumberdaya perikanan akan meningkat dan jika tidak memperhatikan keberlanjutan pemanfaatan sumberdaya perikanan, maka ini akan menimbulkan dampak negatif terhadap kelestarian sumberdaya dan bagi generasi yang akan datang. Oleh karena itu, perlu adanya upaya-upaya yang dilakukan baik oleh pihak pemerintah, non pemerintah dan masyarakat agar tercapainya pemenuhan kebutuhan ekonomi masyarakat saat ini sekaligus juga menjamin ketersediaan ikan untuk generasi mendatang di Kota Tual.

Salah satu bentuk pengelolaan sumberdaya pesisir dan laut yang efektif adalah dengan mengembangkan kawasan konservasi di wilayah pesisir dan pulaupulau kecil. Oleh karena itu Kota Tual berinisiatif untuk mengalokasikan sebagian daerahnya untuk dicadangkan menjadi kawasan konservasi perairan.
Target pembentukan kawasan konservasi perairan Kota Tual yaitu perlindungan terhadap habitat laut penting terdiri dari terumbu karang, lamun dan mangrove, pantai peneluran penyu dan larva connectivity. Kajian ini dilakukan guna mendapatkan lokasi potensial kawasan konservasi perairan yang memiliki nilai konservasi yang tinggi.

Analisis data spatial menggunakan analisis Marxan. Analisis ini dipilih karena marxan merupakan perangkat lunak konservasi yang dapat menemukan lokasi, merancang dan memanajemen kawasan lindung (kawasan konservasi) secara komprehensif mencakup keanekaragaman hayati dalam setiap area (Mace et al, 2006). Marxan digunakan untuk menemukan kawasan konservasi potensial dengan target dan biaya yang paling efisien (Possingham et al., 2012).

\section{METODOLOGI PENELITIAN}

\subsection{Wilayah Kajian}

Analisis dilakukan pada daerah perairan, pesisir dan pulau-pulau kecil yang berada dalam tiga gugus pulau yaitu gugus Pulau Kur, Tayando Tam dan Dullah yang berada di dalam administrasi Kota Tual. Total luas daerah kajian yaitu 993.078 hektar. Wilayah kajian disajikan pada Gambar 1.

\subsection{Analisis Marxan \\ Marxan bekerja menggunakan} algoritma simulated annealing. Algoritma ini memiliki perinsip kerja yang dibagi menjadi tiga langkah yaitu interative, improvement, rendom backward, dan repettion. Ketiga langkah tersebut berfungsi untuk mencari total nilai biaya terendah (Shite et al., 2007). 


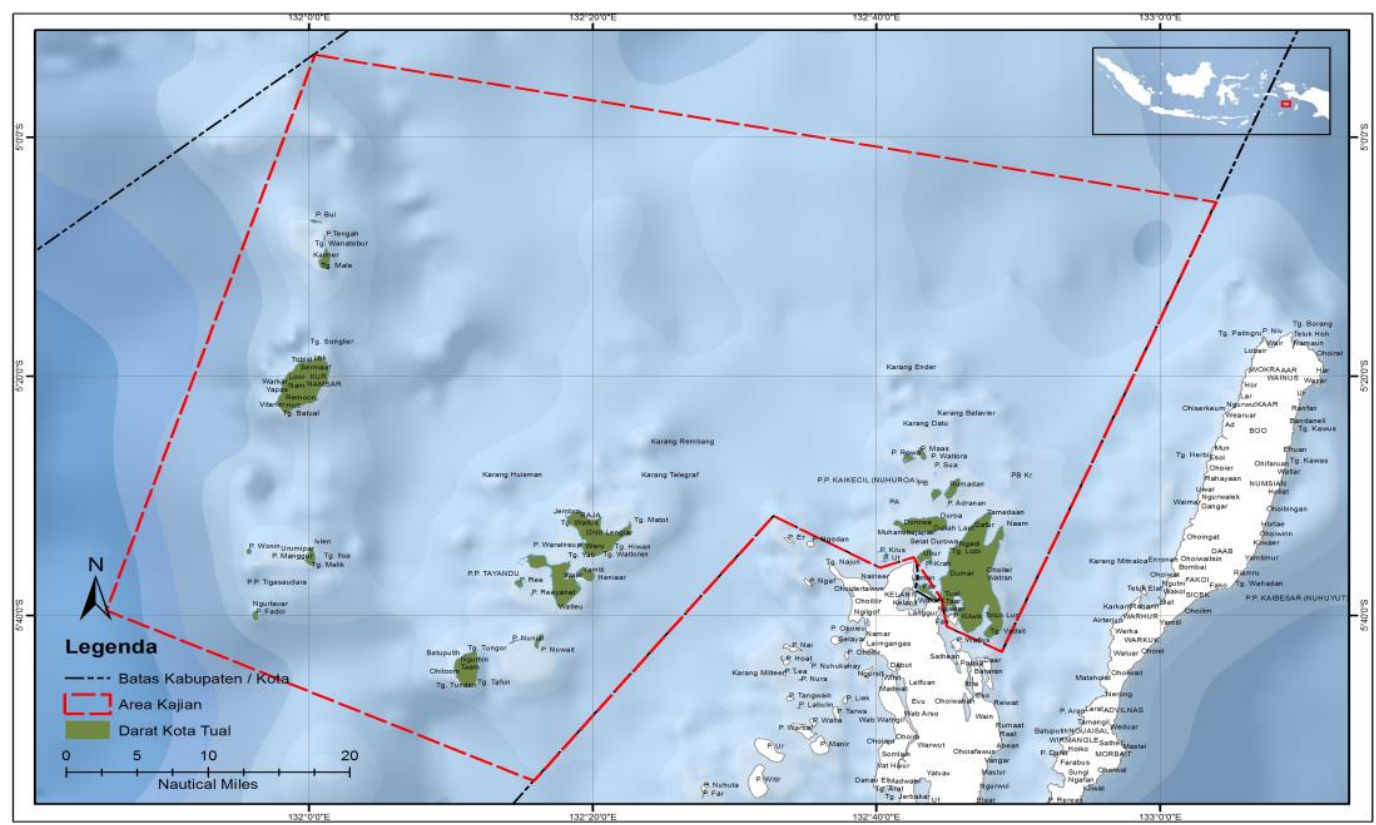

Gambar 1. Wilayah kajian identifikasi lokasi kawasan konservasi Kota Tual

Secara umum algoritma Marxan bekerja dalam empat ketentuan, yaitu sebagai berikut:

$$
\sum \text { Cost }+(\text { BLM }) \sum \text { Boundary Length }+\sum(\text { Species Penalty x SPF })+\text { CTP }
$$

(c)

keterangan :

a) Planning unit Cost adalah nilai kombinasi dari cost sosial ekonomi dari setiap unit perencanaan dalam solusi terpilih

b) Total Boundary Length. Nilai ini merupakan nilai yang diatur oleh pengguna dan berhubungan dengan tingkat konektivitas setiap unit perencanaan. Semakin tinggi nilai yang diberikan akan semakin mengelompok area solusi yang dihasilkan.

c) (c) Species Penalty adalah nilai penalti yang diberikan apabila target perlindungan keanekaragaman hayati tidak tercapai. Sementara Species Penalty Factor (SPF) merupakan nilai yang diatur oleh pengguna yang berhubungan dengan seberapa penting tujuan target perlindungan keanekaragaman hayati. Semakin tinggi SPF diberikan pada suatu fitur, maka marxan akan semakin memprioritaskan target fitur tersebut.

d) Cost Treshold Penalty (CTP) adalah nilai penalti dari solusi yang menghasilkan cost walaupun seluruh target tercapai

e) (Bruce to Milton Transmission Reinforcement Project, 2010).

Analisis yang dihasilkan oleh Marxan memberikan dua keluaran yaitu area terbaik (best selected area) dan area solusi (solutioan area) (Loss, 2006). Area terbaik hanya memberikan satu opsi yaitu terpilih untuk dilindungi atau tidak terpilih untuk dilindungi. Sedangkan area solusi adalah akumulasi dari frekuensi terpilih setiap perencanaan. Semakin tinggi frekuensi terpilihnya sebuah unit perencanaan maka akan semakin tinggi potensi area tersbut untuk dijadikan kawasan lindung. Penggunaan area solusi memberikan keluluasaan dan fleksibilitas bagi 
perencana dalam mendisain kawasan konservasi.

\subsection{Unit Perencanaan (Planning Unit)}

Unit perencanaan merupakan wilayah kajian yang dibagi-bagi menjadi area-area kecil yang meliputi seluruh wilayah kajian. Unit perencanaan merupakan dasar analisis marxan dimana setiap fitur-fitur akan dianalisis diletakkan berdasarkan unit perencanaan. Dalam penelitian ini wilayah kajian dibagi kedalam 1.079 unit perencanaan dengan luas setiap unit perencanaan adalah 1.000 hektar dengan bentuk persegi. Luas unit perencanaan diatur seluas 1.000 hektar agar dapat mempertimbangkan fitur-fitur target yang akan dianalisis seperti area jelajah ikan dan penyu serta spesies biota laut dan sebaran data yang ada. Selain itu faktor efisiensi juga menjadi menjadi pertimbangan dalam menentukan luas unit perencanaan. Semakin kecil luas unit perencanaan, hasil yang dihasilkan akan lebih detail, tetapi ketika marxan dijalankan membutuhkan waktu yang lebih lama.

\subsection{Data dan Skenario}

Data yang digunakan untuk menentukan lokasi kawasan konservasi yang ideal di Kota Tual berupa data primer dan data sekunder. Data tersebut untuk menyusun skenario yang kemudian akan dianalisis marxan. Data primer yang digunakan merupakan hasil survei potensi sumberdaya perikanan dan kelautan Kota Tual tahun 2016 yang diambil berkolaborasi dengan Universitas Pattimura dan Perintah Daerah Kota Tual. Data sekunder dan studi pustaka digunakan untuk memperkuat data primer. Selanjutnya seluruh data akan diterjemahkan kedalam format spatial (shapefile) dalam bentuk area (polygon).

Data target konservasi akan menajadi target berdasarkan persentase luasan total yang akan dilindungi. Persentase tutupan terumbu karang tinggi mendapatkan perlindungan $100 \%$. Pantai peneluran penyu $50 \%$. Untuk data tutupan terumbu karang, lamun dan mangrove serta konektifitas larva diberikan target perlindungan 30\%. Sedangkan untuk data geomorfologi dasar laut target perlindungan sebesar $10 \%$ dan yang terendah adalah jalur migrasi penyu yaitu sebesar 5\%, dikarenakan penyu merupakan hewan yang bermigrasi, maka akan sulit dan membutuhkan area yang besar ketika dilindungi penuh. Proposi target konservasi secara lengkap dapat dilihat pada Tabel 1.

Tabel 1. Fitur konservasi

\begin{tabular}{|c|c|c|c|}
\hline DATA & TARGET (\%) & DESKRIPSI & SUMBER DATA \\
\hline Terraces & 10 & Geomorfologi dasar laut & \multirow{5}{*}{$\begin{array}{l}\text { http://www.bluehabi } \\
\text { tats.org/ } \\
\text { www.worldoceanass } \\
\text { essment.org }\end{array}$} \\
\hline Ridges & 10 & Geomorfologi dasar laut & \\
\hline Escarpments & 10 & Geomorfologi dasar laut & \\
\hline $\begin{array}{l}\text { Shelf } \\
\text { Incising } \\
\text { Carryon }\end{array}$ & 10 & Geomorfologi dasar laut & \\
\hline High Shelf & 10 & Geomorfologi dasar laut & \\
\hline
\end{tabular}




\begin{tabular}{|c|c|c|c|}
\hline DATA & TARGET (\%) & DESKRIPSI & SUMBER DATA \\
\hline $\begin{array}{l}\text { Medium } \\
\text { Shelf }\end{array}$ & 10 & Geomorfologi dasar laut & \\
\hline Biodiversity & 30 & $\begin{array}{l}\text { Konektivitas larva untuk } \\
\text { keanekaragaman hayati }\end{array}$ & \multirow{3}{*}{$\begin{array}{l}\text { Queensland } \\
\text { University \& WWF- ID } \\
2016\end{array}$} \\
\hline Fisheries & 30 & $\begin{array}{l}\text { Konektivitas larva untuk } \\
\text { perikanan }\end{array}$ & \\
\hline $\begin{array}{l}\text { Biodiversity } \\
\text { dan } \\
\text { Fisheries }\end{array}$ & 30 & $\begin{array}{ll}\text { Konektivitas larva } & \text { untuk } \\
\text { keanekaragaman } & \text { hayati } \\
\text { dan perikanan } & \end{array}$ & \\
\hline $\begin{array}{l}\text { Terumbu } \\
\text { Karang }\end{array}$ & 30 & Tutupan terumbu karang & \multirow{3}{*}{ LC EAFM Unpati 2016} \\
\hline Mangrove & 30 & Tutupan mangrove & \\
\hline Lamun & 30 & Tutupan lamun & \\
\hline Dugong & 30 & Lokasi kemunculan dugong & WWF-ID 2016 \\
\hline $\begin{array}{l}\text { Pantai } \\
\text { Peneluran } \\
\text { Penyu }\end{array}$ & 50 & $\begin{array}{l}\text { Lokasi pantai peneluran } \\
\text { penyu }\end{array}$ & LC EAFM Unpati 2016 \\
\hline $\begin{array}{l}\text { Migrasi } \\
\text { penyu }\end{array}$ & 5 & Jalur jelajah penyu & Satelite Tagging \\
\hline $\begin{array}{l}\text { Persentase } \\
\text { tutupan } \\
\text { terumbu } \\
\text { karang }\end{array}$ & 100 & $\begin{array}{l}\text { Persentase tutupan } \\
\text { terumbu karang tinggi }\end{array}$ & $\begin{array}{l}\text { LC EAFM Unpati } 2016 \\
\text { dan WWF-ID } 2015\end{array}$ \\
\hline
\end{tabular}

Selain data target konservasi yang digunakan adapula data pemanfaatan (cost) ruang yang bertentangan dengan konservasi. Data cost yang digunakan antara lain, area pemanfaatan perikanan berdasarkan alat tangkap (pancing, jaring, bubu dan bagan), area pengeboman ikan, budidaya mutiara, pelabuhan, desa pesisir dan lokasi tekanan perikanan (tinggi, sedang dan rendah).

Setelah data spatial target konservasi dan cost terkumpul, data-data tersebut dianalisis lebih lanjut untuk mengidentifikasi lokasi-lokasi yang memiliki nilai konservasi tinggi. Analisis menggunakan perangkat lunak Marxan dan Zonae Cogito.

\subsection{Perangkat Lunak}

Perangkat lunak yang digunakan dalam kajian ini antara lain, Quantu GIS 1.8 Lisboa, Marxan dan Zonae Cogito. Quantum GIS digunakan untuk menyiapkan data-data spatial dengan menggunakan bantuan fitur plugin QMarxan yang terpasang dalam QGIS. Proses analisis menggunakan Marxan.exe. Zonae Cogito digunakan untuk melakukan modifikasi secara lebih leluasa terhadap hasil-hasil yang diperoleh dari proses 
eksekusi menggunakan Marxan.exe. Zonae Cogito menyediakan fitur untuk melakukan perubahan terhadap SPF, BLM, proporsi target dan Cost (Kircher et al., 2012).

\section{HASIL DAN DISKUSI}

Hasil analisis marxan menunjukan bahwa area solusi yang memiliki frekuensi tinggi atau area dengan nilai keanekaragaman hayati tinggi yaitu seluas 125.000 hektar, sedangkan frekuensi sedang 40.000 hektar dan frekuensi rendah 64.000 hektar. Hasil analisis dapat dilihat pada Gambar 2. Sedangkan untuk target konservasi yang terlindungi dapat dilihat pada Tabel 2. Tabel 2 menunjukan pada frekuensi prioritas tinggi memiliki luasan target-target yang akan dikonservasi lebih tinggi dibandingkan dengan prioritas sedang.

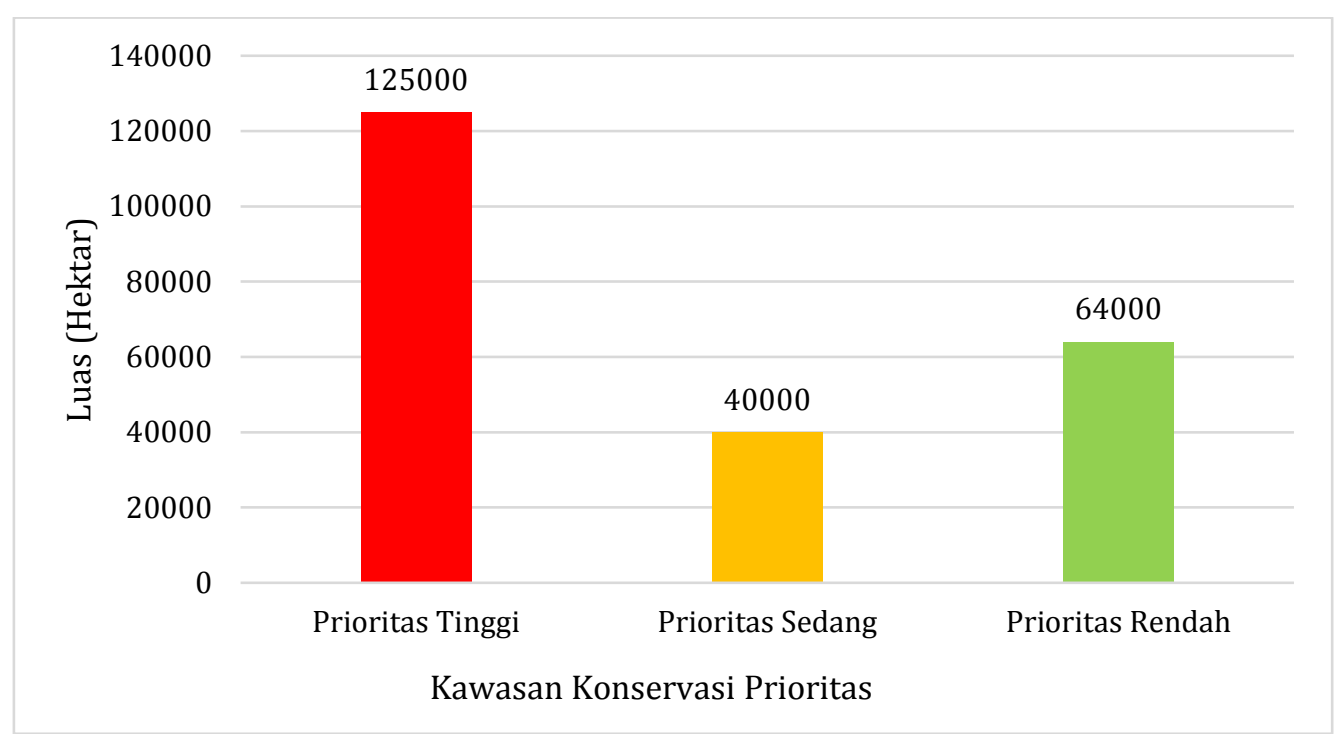

Gambar 2. Perbandingan luas area solusi terpilih prioritas tinggi, sedang dan rendah

Tabel 2. Luas area target konservasi hasil analisis yang terlindungi

\begin{tabular}{lcc}
\hline \multicolumn{1}{c}{ Data } & Prioritas Tinggi (Ha) & Prioritas Sedang (Ha) \\
\cline { 2 - 3 } Terraces & 8.796 & 10.237 \\
Ridges & 72.280 & 11.836 \\
Escarpments & 11.011 & - \\
Shelf Incising Canyon & 8.260 & 1.922 \\
High Shelf & 21.643 & 9.052 \\
Medium Shelf & 1.237 & - \\
Larva konektivitas untuk & 29.810 & 7.490 \\
keanekaragaman hayati & & 3 \\
Larva konektivitas untuk & 30.227 & 3 \\
perikanan & &
\end{tabular}




\begin{tabular}{lcc}
\hline \multicolumn{1}{c}{ Data } & Prioritas Tinggi (Ha) & Prioritas Sedang (Ha) \\
\cline { 2 - 3 } Larva konektivitas untuk & 60.038 & 10.490 \\
keanekaragaman hayati & 1.087 & 271 \\
dan perikanan & 41 & 8 \\
Terumbu Karang & 861 & 192 \\
Mangrove & 42.090 & 12.185 \\
Lamun & 173 & 59 \\
Dugong & 3.005 & 1.317 \\
Pantai Peneluran Penyu & 15 & - \\
Migrasi Penyu & & \\
Persentase Tutupan & & \\
Terumbu karang & & \\
\hline
\end{tabular}

Lokasi prioritas tinggi yang dihasilkan dari area solusi terbaik ada dua lokasi yang direkomendasikan menjadi kawasan konservasi yang berada diperairan Kota Tual. Rekomendasi pertama yaitu berada di gugus pulau-pulau Kur dan Tayando Tam sedangkan rekomendasi kedua berada di sebelah utara perairan Pulau Mas dan Pulau Bair. Deliniasi rekomendasi lokasi kawasan konservasi hasil analisis dapat dilihat pada Gambar 3.

Rekomendasi 1 calon kawasan konservasi perairan dan pulau-pulau kecil di Kota Tual berada di gugus pulau-pulau Kur dan Tayando Tam dengan luas calon kawasan 268.577 hektar. Pada calon kawasan ini memiliki tiga habitat pesisir yaitu terumbu karang 2.739 hektar, lamun 133 hektar dan mangrove 115 hektar. Pantai yang berada di pesisir pulau-pulau kecil yang berada di gugus pulau ini menjadi lokasi pendaratan penyu untuk bertelur dan pesisirnya menjadi lokasi makan (feeding ground) dari mamalia laut dugong. Sedangkan bagian perairannya menjadi jalur migrasi penyu. Serta lokasi rekomendasi konektivitas larva untuk keanekaragaman hayati, perikanan dan keduanya Lokasi rekomendasi 2 kawasan konservasi yang berada di perairan Kota
Tua berada disebalah utara Pulau Mas dan Pulau Bair dengan luas 90.485 hektar. Lokasi ini hanya memiliki satu habitat penting yaitu terumbu karang dengan luas 99 hektar yang berada di tengah laut sedangkan habitat lainya seperti lamun dan mangrove tidak ditemukan pada lokasi ini. Lokasi ini juga menjadi jalur lokasi migrasi penyu.

\section{KESIMPULAN}

Marxan memberikan dua rekomendasi area prioritas untuk desain kawasan konservasi perairan dan pulapulau kecil yang berada di Kota Tual. Lokasi rekomendasi satu menjadi lokasi potensial karena dapat mengakomodasi dari target pembentukan kawasan konservasi di Kota Tual, yaitu dengan melakukan perlindungan terhadap habitat pesisir (terumbu karang, lamun dan mangrove), pantai peneluran penyu dan lokasi potensial konektivitas larva. Analisis ini dapat dijadikan rekomendasi dan arahan bagi pemerintah, masyarakat dan pihak-pihak terkait untuk dijadikan bahan rekomendasi inisiasi pembentukan kawasan konservasi yang berada di Kota Tual. 


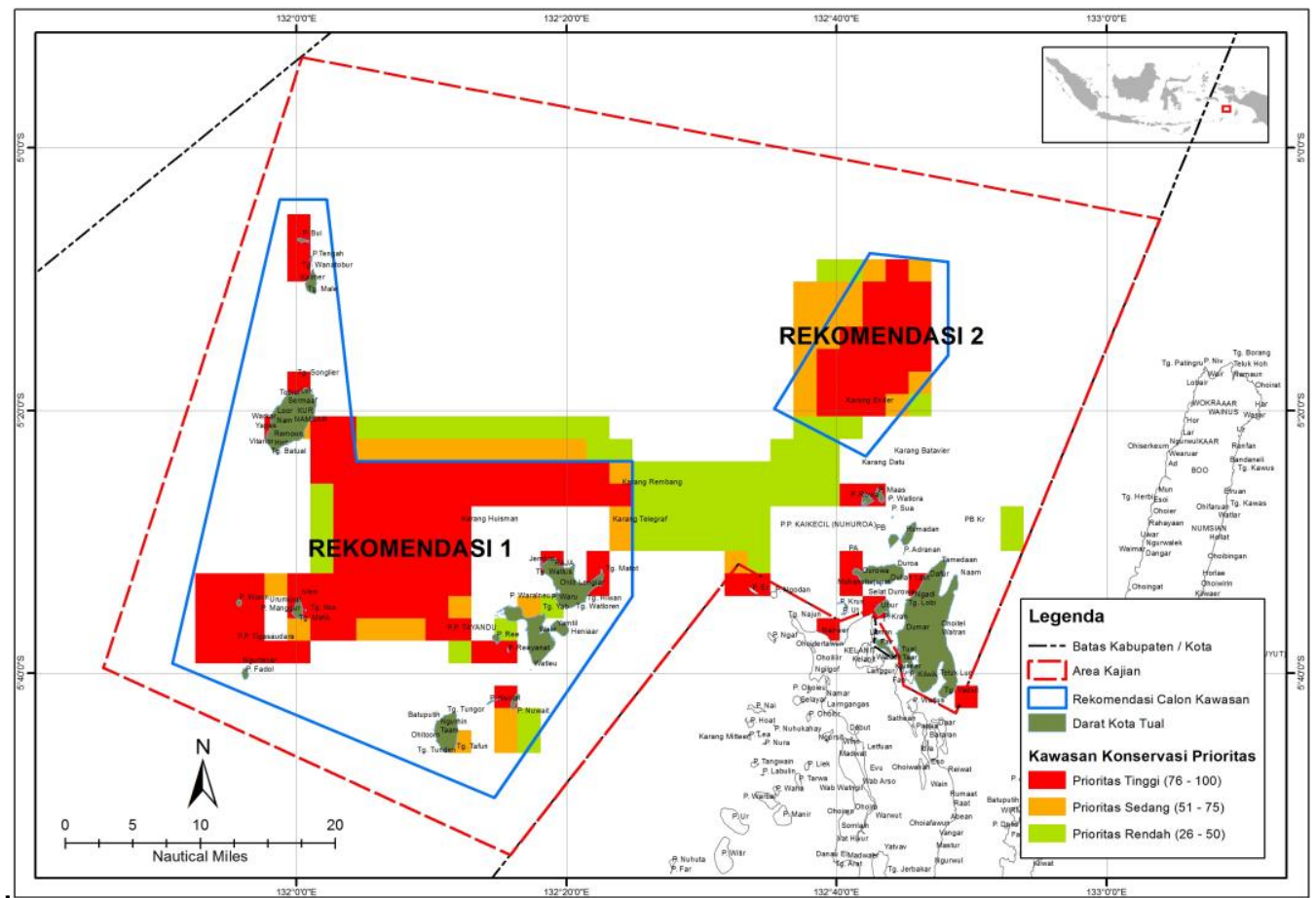

Gambar 3. Rekomendasi lokasi kawasan konservai Kota Tual

\section{UCAPAN TERIMA KASIH}

Ucapan terimakasih penulis sampaikan kepada pemerintah Kota Tual dalam rangka mencari lokasi perairan yang potensial untuk dicadangkan menjadi kawasan konservasi perairan. Dinas Perikanan Kota Tual, Learning Center EAFM Universitas Pattimura dan WWF Indonesia untuk data yang diberikan guna menjadi bahan analisis dalam karya tulis ini.

\section{DAFTAR PUSTAKA}

Badan Pusat Statistik. 2016. Kota Tual Dalam Angka 2016. BPS Kabupaten Maluku Tenggara. Langgur. 375 p.

Bruce. (2010), Appendix A: MNR Landscape Conservation Planning Analysis, Bruce to Milton Reinforcement Project, Biodiversity Initiative Opportunity Evaluation and Rangking.
Kircher, Matthew.W.L. Game, Eddie. And Segan, Dan. (2012). Introduction to Marxan Course Manual Day 2. Centre for Biodiversity \& Conservation Science, University of Queensland. 40 p.

Loss, S. A. 2006. Exploration of Marxan Utility in Marine Protected Area Zoning. Tesis. University of Victoria. Saanich. 199 p.

Possingham, H.P et al. (2010), Introduction. In Marxan Good Practices Handbook Version 2, Ardron, Jeff A., Possingham, H.P., and Klein, Carrisa J. (eds). Pacific Marine Analysis and Research Association, Victoria, BC, Canada. 155 p.

Shite, J., Darmawan, A., dan Subijanto, J. 2007. Marxan Untuk Perancangan Jejaring Kawasan Konservasi Laut Di Wilayah Lesser Sunda (Bali, NTB, NTT, NTT, Tiomr Leste). Geo-Marine Research Forum. 373-384 